\title{
Perception of 'Comprehensiveness of Care': a qualitative study amongst dentists in the Brazilian Health System
}

\section{Grazielle Christine Maciel MATTOS(a) \\ Jennifer Elizabeth GALLAGHER ${ }^{(\mathrm{b})}$ \\ Saul Martins PAIVA(c) \\ Mauro Henrique Nogueira \\ Guimarães de ABREU(a)}

(a) Universidade Federal de Minas Gerais UFMG, School of Dentistry, Department of Community and Preventive Dentistry, Belo Horizonte, MG, Brazil.

(b)King's College London, Dental Institute, Department of Dental Public Health, London, United Kingdom.

(c) Universidade Federal de Minas Gerais UFMG, School of Dentistry, Department of Orthodontics and Pediatric Dentistry, Belo Horizonte, MG, Brazil.

Declaration of Interests: The authors certify that they have no commercial or associative interest that represents a conflict of interest in connection with the manuscript.

\section{Corresponding Author:}

Mauro Henrique Nogueira Guimarães Abreu E-mail:maurohenriqueabreu@gmail.com

DOI: 10.1590/1807-3107BOR-2015.vol29.0037

Submitted: Mar 26, 2014

Accepted for publication: Nov 14, 2014

Last revision: Jan 09, 2015

\begin{abstract}
Comprehensiveness relates both to the scope of services offered and to a holistic clinical approach. The aim of this study was to identify the perception of Brazilian dentists regarding key concepts of comprehensiveness and its importance in primary health care oral health services performed in the public sector. Focus groups were conducted to explore three main concepts, 'patient welcoming', 'bonding' and 'quality of care', as well as their aspects. In total, there were four focus groups comprising seven general dentists, all of whom had at least two years of experience in primary care, from municipalities of varying sizes. Discussions of approximately 60 minutes were conducted, audio-recorded and transcribed. The data were analysed by qualitative thematic analysis, in line with the framework approach. The general dentists reported that they are aware that in the Brazilian Health System, the onset of patient care by primary health care services must happen through 'patient welcoming.' Nevertheless, they suggested that this action is often performed poorly due to the large volume of patients. Although they knew the importance of 'bonding', they realised that there is a lack of education preparing professionals to address interpersonal and social issues. They were aware that 'quality of care' is related to multiple factors. Comprehensiveness, as an approach in dental public health practices, needs to be enhanced, and there is evidence that primary care dentists are aware of the need for such an approach.
\end{abstract}

Keywords: Comprehensive Health Care; Oral Health; Primary Health Care; Public Health; Qualitative Research.

\section{Introduction}

Comprehensiveness is used as a general quality indicator of Primary Health Care and is also considered one of the principles of the Brazilian Health System. ${ }^{1}$ To obtain any measurement strategy to assess how well comprehensiveness is understood and achieved, it is essential to have a clear operational definition of the concept, especially among human resources. ${ }^{2}$

The term is defined from two different perspectives: the first is the comprehensive services, and the second is whole-person care. ${ }^{2,3}$ The interpretation of and debate about the meanings of comprehensiveness are all derived from the relationships between patients, health professionals and managers within the service. These interrelations converge at the 
level of the health care model, which should be conceived and developed from interpersonal tools such as 'patient welcoming' and 'bonding'.,5

Thus, comprehensiveness exists in act and can be sought in the organisation of services and renewal of health practices. In this sense, it must be recognised in strategies to improve the access to and development of integrated practices. ${ }^{1,4,5}$ General concepts of 'patient welcoming,' 'bonding' and 'quality of care' have been applied and used to evaluate the comprehensiveness approach. ${ }^{1,25,6,7}$

It is important for the comprehensiveness element to be reinforced in the critical awareness of health professionals and the community to enable the realisation of transformative actions. ${ }^{2,5}$ The importance of comprehensiveness for oral health outcomes involves strengthening community actions, developing personal skills and reorienting health services. This approach could also generate a longer lasting, effective and efficient treatment, decreasing the likelihood of a patient returning in a short time. It is necessary to understand that having oral health means that a person can fully exercise functions such as mastication, swallowing and speech, as well as exhibit self-esteem and interact socially without inhibition or embarrassment, all of which contribute to the person's general health. ${ }^{8}$ In this study, we aimed to identify the perception of Brazilian general dentists on concepts of comprehensiveness and its importance in primary health care oral health services performed in the public sector. In addition, we intended to explore the outcomes of this study to generate items for an instrument to evaluate primary care from the viewpoint of a dentist, based on key concepts related to 'comprehensiveness of care'.

\section{Methodology}

This study was submitted to and approved by the Ethics Committee for Human Research of the Municipality of Belo Horizonte and the Universidade Federal de Minas Gerais - UFMG (protocol number 0437.0.203.410-11A).

This study reports the first phase of a larger research project that is currently in progress and aims to develop a tool to assess primary care from domains related to comprehensiveness of care from the dentist's perspective. Parallel studies are examining patient perspectives.

The setting for this research was the city of Belo Horizonte in southeastern Brazil. It is a large city, with an area of $330 \mathrm{~km}^{2}$ and approximately $2,400,000$ inhabitants. Data collection occurred between November and December 2011. The main authors, a female $\mathrm{PhD}$ student and a male professor with experience in qualitative studies, facilitated the focus group sessions. The data were obtained through four focus group sessions; $;, 10$ the groups comprised a self-selected sample of seven general dentists, each with a minimum of two years primary health care experience in the public sector. The seven dentists attended all four focus group sessions.

In addition to meeting the inclusion criteria, the general dentists also proportionally represented the varying populations of the range of municipalities across Brazil. The sample comprised one dentist who works in a city of up to 20,000 inhabitants, two in cities with populations ranging from 20,001 to 100,000 inhabitants, two in cities with populations of 100,001 to 500,000 inhabitants and two in municipalities with more than 500,000 inhabitants.

The variation of the composition aims to make the discussion as generalisable as possible because Brazil is a country of continental dimensions and the perception of comprehensiveness of care by the professional may differ according to the realities in which s/he operates. ${ }^{9,10}$

We established initial parameters to define which domains related to comprehensiveness would be discussed. Focus groups were used to explore the following three main concepts: 'patient welcoming' (act of receiving the patient in the clinic and responding to his/her problem), 'bonding' (link between the patient and the health service) and 'quality of care'. Figure 1 shows the main domains considered by the framework and the aspects that propose an operational and structural link between the concepts of primary care as a way to evaluate the daily routine of services and professional practices, as well as their relationship with the population. . $^{1,2,3,5}$

Three main domains of comprehensiveness of care ('patient welcoming', 'bonding', 'quality of care') were explored in the first three groups. The fourth group aimed to discuss the relationship between the three 


\begin{tabular}{|c|c|c|}
\hline$\downarrow$ & Comprehensiveness & 7 \\
\hline Patient welcoming & Bonding & Quality of care \\
\hline $\begin{array}{c}\text { Access } \\
\text { Geographical } \\
\text { Organisational } \\
\text { Posture } \\
\text { Listening } \\
\text { Professional-patient attitude } \\
\text { Intra-team relationship } \\
\text { Technique } \\
\text { Teamwork } \\
\text { Training of professionals } \\
\text { Acquisition of technology, knowledge } \\
\text { and practices } \\
\text { Reorientation of services } \\
\text { Institutional project } \\
\text { Supervision } \\
\text { Work process }\end{array}$ & $\begin{array}{c}\text { Affectivity } \\
\text { Appreciation for the profession } \\
\text { Interest in the patient's person } \\
\text { Professional-patient bond } \\
\text { Continuity } \\
\text { Expectations and perceptions of the patient } \\
\text { Acceptance and trusting interrelation } \\
\text { Adherence to treatment } \\
\text { Uniqueness of the patient } \\
\text { Therapeutic relationship } \\
\text { Efficacy of treatment } \\
\text { Patient as a subject in the treatment process } \\
\text { Professional-patient trust } \\
\text { Attitude of care } \\
\text { Abandonment reduction }\end{array}$ & $\begin{array}{c}\text { Professional conduct } \\
\text { Technical qualification Technical/ } \\
\text { socio-environmental care } \\
\text { Continuity of care } \\
\text { Professional-patient relationship } \\
\text { Patient satisfaction } \\
\text { Expectations } \\
\text { Adjustment/Flexibility Professional } \\
\text { Satisfaction }\end{array}$ \\
\hline
\end{tabular}

Figure 1. Domains and aspects related to comprehensiveness to be addressed in the assessment of oral health in Primary Health Care.

concepts. The focus group sessions, which lasted approximately 60 minutes, were audio-recorded and transcribed. Aside from these first-described domains, no other domain resulted from the discussions. Interview recordings and transcripts were analysed by content analysis. ${ }^{9,10}$ The transcribed material was systematically analysed. The themes were identified in advance: 'the process and difficulties of patient welcoming', 'relationship and bonding' and 'the multiple meanings of quality of care'. The interpretation of the results was carried out by the researchers as a team. Saturation was identified in the data.

Excerpts of the transcripts from the sessions were translated into English by a native Brazilian Portuguese speaker who is also fluent in the English language. The excerpts were checked by a native English speaker, and the latest version of this manuscript was submitted to a specialised company in English language translations.

\section{Results}

In this study, general dentists demonstrated an awareness of the importance of all oral health team members performing patient welcoming actions.
Nevertheless, they also reported that 'patient welcoming' is often executed in isolation, sometimes only by dental assistants or oral health technicians and seldom by dentists.

\footnotetext{
'In my clinic, we performed, the oral health team performs patient welcoming daily, so it is the starter, or gateway, to the service for the user/patient. Sometimes, we do it separately. The patient looks for the dental service, and we welcome him (...)' (Participant A).
}

Respondents considered that the education process is deficient in the development of communication and interpersonal skills, and many students are not aware of the social aspects of the patient's health and are not adequately prepared to embrace interdisciplinary social health-based education/training.

\footnotetext{
'During undergraduate courses, we were well trained clinically, but when that moment comes, you have to learn what patient welcoming and bonding are, as well as learn solidarity, which are important and widely used today. We don't learn this in college. When we work in public service, we have to develop it (...)' (Participant A).
} 
In relation to how the health service is organised and how patient welcoming actions are developed, all general dentists reported that they were aware that in the Brazilian Health System, the onset of patient care by a primary health care service must happen through 'patient welcoming.' Nevertheless, they also reported that this action is often impaired and performed poorly due to the high volume of patients who seek health services daily.

\footnotetext{
'We perform patient welcoming. There is a registration of the patients. They go to the health clinic to register, and we call them when appointments become available. However, the demand is so high that the patient often waits for treatment for about three months (...)' (Participant B).
}

Dentists also showed that they are aware of the importance of solid, trusting relationships between professionals and patients in primary health care services.

\footnotetext{
'Bonding is very important because, through it, we can ensure the patient's confidence in you, creating the bond of trust and making it easier for patients to assimilate all that you teach them, all that you speak. By doing this, you empower your patient' (Participant E).
}

'To the extent that you know the patient's expectations, perceptions, and interests, as well as the reality in which $\mathrm{s} /$ he lives and in which each one of your patients lives, you can better target your speech, techniques, and strategies to build a relationship of trust and, in the end, an attitude of healthcare with the patient in the treatment process to obtain treatment efficacy, adherence and dropout reduction' (Participant G)

Participants also suggested that although they knew the importance of 'bonding' in primary health care, they realised that their education poorly prepares professionals to address issues of an interpersonal and social nature.

'Often, dentists leave college without adequate preparation to build a connection with the patient. Unfortunately, our universities are just preparing professionals for clinical care in the office. They do not have consistent health policy teachings, and they do not provide social practice (Participant G).

In the analysis, the dentists demonstrated awareness that 'quality of care' is related to multiple factors.

'I think that quality of care has to be taken into consideration. In addition to issues of human values and human resources, infrastructure must be considered. You need an infrastructure that provides you with the materials you need, as well as human resources...' (Participant G).

'I think the quality of health services also depends on infrastructure, the materials we have, professional training and the patient's expectations, too...' (Participant B).

The participants showed concern and emphasised that healthcare services should be shaped to achieve patient satisfaction. In this approach, under the professional viewpoint, quality of care is also established as satisfying patient expectations and needs.

'It is important to listen to the patient to try to understand what this patient is looking for and to try to supply what he is seeking. The combination of these factors characterises the quality of care...' (Participant F).

\section{Discussion}

The research findings provide an overview about dentists' perception of 'comprehensiveness of care". In summary, the dentists knew the concepts, perceived the importance of the three domains of comprehensiveness, considered that the quality of dental education regarding some issues is of concern and revealed that the practice of 'comprehensiveness of care' is far from ideal.

The isolation of the working process of welcoming patients is of concern. In health care settings, human resources from diverse backgrounds come together to care for patients, including the dentist, dental assistant and oral health technician, in primary oral healthcare offices. Health care involves groups of people working together; therefore, research shows that a group with strong teamwork tends to perform better than a group lacking teamwork. Primary healthcare teams with clear targets and healthy communication did 
better than less cohesive groups on patient-perceived quality and patient satisfaction. 11,12,13,14 The patient- and family-centred care models underscore the essential characteristics of healthcare communication, which relies heavily on core communication skills such as open-ended inquiry, reflective listening and empathy as a way to respond to the individual needs, values and preferences of patients. ${ }^{12,15,16}$

Welcoming in health, unlike in triage, involves receiving patients with attention, time and willingness to listen and valorise the particularities of each patient. This means fostering conditions for suffering patients to express their problems, presupposing the need for returns and assessing the family and social context of the individual to develop a therapeutic plan. ${ }^{17}$ The dental workforce requires more than knowledge and training to carry out good quality of care; it also requires infrastructure, supplies and management support. All of these interrelated factors affect the quality of care that is provided. ${ }^{18}$

Relationships in health care, as evaluated by some studies exploring the familiarity of physicians with their patients, indicated that a deeper understanding of patients led to more efficient and effective care, which resulted in an enhanced sense of professional competence. This competence included their ability to interpret their patients' nonverbal cues, their existing working knowledge of their patients and their ability to prioritise issues and provide personalised care. Knowing their patients well allowed the professionals to predict how they might react in a particular situation by measuring their reactions and therefore decreasing their anxiety. ${ }^{16,19}$ The construction of 'bonding' is grounded in the fundamentals of affectivity, continuity and therapeutic relationships; this depends on both the patients and the health team, and, in our research, the dentists know the importance of these characteristics. ${ }^{1,4,5}$ As we highlighted in discussing the patient welcoming domain, dentists of the future will need to be oral physicians with interpersonal skills, as well as dental surgeons who direct the dental health team to provide holistic, patient-centred care that supplements general healthcare provisions. This requires the prompt embrace of a new approach of workforce enhancement and development. ${ }^{13,14}$

From the perspective of comprehensiveness, 'quality of care' must involve an idealised model that takes an articulated set of actions into account, which has proven to be effective in certain situations of health and illness, was developed within a relationship of trust and acceptance between staff and patients and is being perceived as satisfactory by the staff and patients. ${ }^{5,1}$ Therefore, 'quality of care' in health services depends on the service process, as well as the interactions between the customer and the service provider. ${ }^{21}$

One of the most robust approaches to assess 'quality of care' is through the framework of Donabedian, ${ }^{21}$ who established the following three components for assessment: technical quality, which is the effectiveness of care in producing reachable health gains; interpersonal quality, which requires meeting patient needs and preferences; and amenities, which includes physical environment and organisational characteristics. In our research, dentists also associated the quality assessment with the pillars considered by Donabedian. ${ }^{21}$

In summary, 'quality of care' can be assessed by both the service characteristics that meet predetermined specifications and standards and the features that meet or exceed the customer needs and expectations. In a broader overview, quality of care highlights that healthcare delivery is shaped by providers, regulators, clients and suppliers. Therefore, the views and priorities of healthcare stakeholders must be considered in an effort to establish, gauge and improve quality of care. ${ }^{1,21}$

This study has a number of limitations. First, it only relates to one area of Brazil, Belo Horizonte and its metropolitan area. Second, the dentists participating in the focus groups were self-selected; however, this was improved by gaining geographic representation across the region. Thus, the study outcomes might be harder to generalise to a larger population without formally testing them through research. By nature, focus group research is open-ended and thus cannot be completely predetermined., ${ }^{910}$ Nevertheless, this study did raise important issues that support policy literature on this issue, suggesting that these findings could contribute to 
the debate on primary dental care in Brazil; additionally, these findings address gaps in the Brazilian literature. ${ }^{1,4,22}$

Furthermore, although one would expect a self-selecting group to be more interested in these concepts, it was clear from the findings that they did not believe they were adequately delivering them, partly due to the volume of patient care. The high volume of patients every day for patient welcoming, the lack of adequate infrastructure to address this number of patients and the lack of better teamwork skills all represent problems in the clinical settings that might hinder the application of concepts and tools to improve and optimise clinical care.

The findings suggest that education might play a role in these issues. The curriculum disciplines of several dental schools still retain vestiges of the biomedical model focuses on disease; these disciplines should be modernised and focused on strengthening the relationships and comprehensive care of professionals with the patients. In addition to introducing communicative and teamwork skills, these disciplines should adequately prepare new dentists who will work in the public sector. ${ }^{4}$

Our results might be useful in further understanding how to evaluate the process of care, as well as how the perceptions of dentists could contribute to

\section{References}

1. Silva Junior AG, Alves MGM, Mascarenhas MTM, Silva VMN, Carvalho LC. Evaluation experiences of the supplementary care sector: contributions of integrality. Cien Saude Colet. 2008 Sep-Oct;13(5):1489-500. Portuguese.

2. Haggerty J, Burge F, Lévesque JF, Gass D, Pineault R, Beaulieu $\mathrm{MD}$, et al. Operational definitions of attributes of primary health care: consensus among Canadian experts. Ann Fam Med. 2007 Jul-Aug;5(4):336-44.

3. Haggerty JL, Beaulieu MD, Pineault R, Burge F, Lévesque JF, Santor DA, et al. Comprehensiveness of care from the patient perspective: comparison of primary healthcare evaluation instruments. Healthc Policy. 2011 Dec;7(Spec Issue):154-66.

4. Santos AM, Assis MMA. Da fragmentação à integralidade: construindo e (des) construindo a prática de saúde bucal no Programa de Saúde da Família (PSF) de Alagoinhas, BA. Cien Saude Colet. 2006 Jan-Mar;11(1):53-61.

5. Dickinson WP, Miller BF. Comprehensiveness and continuity of care and the inseparability of mental and behavioral improvements in primary oral health care. In future studies, the perceptions of dentists from different parts of Brazil, as well as of other nationalities, should be researched to enrich and strengthen the data obtained and to broaden the discussion into the private sector. This analysis is important for each group involved in the provision of services; therefore, further analysis or research is needed to analyse health services from different perspectives. Checking our research findings with other representative studies will raise the reliability of this study.

The findings of this research might contribute to the development of robust instruments to be used by health services to successfully maintain and control the care that is provided to the population.

\section{Conclusion}

Identifying and exploring the knowledge of Brazilian general dentists about comprehensiveness and its importance in primary oral health care are major approaches to be taken into consideration in the assessment of care offered to the population in the public health sector. The findings suggest that comprehensiveness, as an approach in the dental public health practice, needs to be enhanced and that the general dentists in this study are aware of this issue.

health from the patient-centered medical home. Fam Syst Health. 2010 Dec;28(4):348-55.

6. Aller MB, Colomé JM, Waibel S, Vargas I, Vázquez MLA. First approach to differences in continuity of care perceived by immigrants and natives in the Catalan public healthcare system. Int J Environ Res Public Health. 2013 Apr 9;10(4):1474-88.

7. Guthrie B, Saultz JW, Freeman GK, Haggerty JL. Continuity of care matters. BMJ. 2008 Aug;337:a867.

8. Petersen PE. The World Oral Health Report 2003: continuous improvement of oral health in the 21st century-the approach of the WHOGlobal Oral Health Programme. Community Dent Oral Epidemiol. 2003 Dec;31 Suppl 1:3-23.

9. Carter SM, Ritchie JE, Sainsbury P. Doing good qualitative research in public health: not as easy as it looks. NS W Public Health Bull. 2009 Jul-Aug;20(7-8):105-11.

10. Blignault I, Ritchie J. Revealing the wood and the trees: reporting qualitative research. Health Promot J Austr. 2009 Aug;20(2):140-5. 
11. Goñi S. An analysis of the effectiveness of Spanish primary health care teams. Health Policy. 1999 Aug;48(2):107-17.

12. Grumbach K, Bodenheimer T. Can health care teams improve primary care practice? JAMA. 2004 Mar;291(10):1246-51.

13. Gallagher J, Wilson N. The future dental workforce? Br Dent J. 2009 Feb;206(4):195-9.

14. Franzén C. Boundary work of dentists in everyday work. Community Dent Oral Epidemiol. 2012 Aug;40(4):377-84.

15. Zwarenstein M, Goldman J, Reeves S. Interprofessional collaboration: effects of practice-based interventions on professional practice and healthcare outcomes. Cochrane Database Syst Rev. 2009;3(CD000072).

16. Schultz K, Delva D, Kerr J. Emotional effects of continuity of care on family physicians and the therapeutic relationship. Can Fam Physician. 2012 Feb;58(2):178-85.

17. Mangia EF, Souza DC, Mattos MF, Hidalgo VC. Acolhimento: uma postura, uma estratégia. Rev Ter Ocup Univ São Paulo. 2002 Jan-Abr;13(1):15-21.
18. Rowe AK, Savigny D, Lanata CF, Victora CG. How can we achieve and maintain high-quality performance of health workers in low-resource settings? Lancet. 2005 Sep;366(9490):1026-35.

19. Catty J, Cowan N, Poole Z, Ellis G, Geyer C, Lissouba P, et al. Attachment to the clinical team and its association with therapeutic relationships, social networks, and clinical well-being. Psychol Psychother. 2012 Mar;85(1):17-35.

20. Mosadeghrad AM. Healthcare service quality: towards a broad definition. Int J Health Care Qual Assur. 2013 Mar;26(3):203-19.

21. Donabedian A. Explorations in quality assessment and monitoring. Vol.1, The definition of quality and approaches to its assessment. Ann Arbor: Health Administration Press; 1980. $163 \mathrm{p}$.

22. Nascimento AC, Moysés ST, Bisinelli JC, Moysés SJ. Saúde bucal na estratégia de saúde da família: mudança de práticas ou diversionismo semântico. Rev Saude Publica. 2009 Jun;43(3):455-62. 